\title{
Transcriptome Profiling for Pericarp Browning During Long-term Storage of Intact Lotus Root (Nelumbo Nucifera)
}

Kanjana Worarad ( $\sim$ kanjana1304@gmail.com )

Ibaraki University

Tomohiro Suzuki

Utsunomiya University

Haruka Norii

Ibaraki University

Yuya Muchizuki

Ibaraki University

Takashi Ishii

Ibaraki Agriculture Center

Keiko Shinohara

Tokushima Horticulture

Takao Miyamoto

Renkon3kyodai

Tsutomu Kuboyama

Ibaraki University

Eiichi Inoue

Ibaraki University Library Mito Main Library: Ibaraki Daigaku Toshokan Honkan Mito Campus

\section{Research Article}

Keywords: Browning disorder, RNA sequencing, Transcriptomics, Postharvest physiology

Posted Date: May 25th, 2021

DOI: https://doi.org/10.21203/rs.3.rs-539513/v1

License: (c) (i) This work is licensed under a Creative Commons Attribution 4.0 International License.

Read Full License

Version of Record: A version of this preprint was published at Plant Growth Regulation on August 11th, 2021. See the published version at https://doi.org/10.1007/s10725-021-00736-2. 

1 Transcriptome profiling for pericarp browning during long-term storage of intact lotus root (Nelumbo

2

4

5 nucifera)

3 Kanjana Worarad ${ }^{1}$, Tomohiro Suzuki ${ }^{2}$, Haruka Norii ${ }^{1}$, Yuya Muchizuki ${ }^{1}$, Takashi Ishii ${ }^{3}$, Keiko Shinohara ${ }^{4}$, Takao

Miyamoto $^{5}$, Tsutomu Kuboyama ${ }^{1}$, Eiichi Inoue ${ }^{1 *}$

.

${ }^{1}$ College of Agriculture, Ibaraki University, Ami, Ibaraki 300-0393, Japan.

${ }^{2}$ Center for Bioscience Research and Education, Utsunomiya University, Utsunomiya, Tochigi 321-8505,

Japan.

${ }^{3}$ Ibaraki Agricultural Center, Horticultural Research Institute, Mito, Ibaraki 310-8555, Japan.

${ }^{4}$ Tokushima Agriculture, Forestry and Fisheries Technology Support Center, Ishii, Tokushima 779-3233,

Japan.

$2{ }^{5}$ Renkon3kyodai Co.Ltd, Japan.

* Corresponding author

Email addresses: eiichi.inoue.a@vc.ibaraki.ac.jp (EI)

Authors

Email addresses: kanjana1304@gmail.com (KW)

Email addresses: suzukit@cc.utsunomiya-u.ac.jp (TS)

8 Email addresses: haruka.norii@gmail.com (HN)

9 Email addresses: yuya.mochizuki.fuji@vc.ibaraki.ac.jp (YM)

20 Email addresses: ta.ishii@pref.ibaraki.lg.jp (TI)

1 Email addresses: shinohara_keiko_1@pref.tokushima.jp (KS)

2 Email addresses: mail@renkon3kyodai.com (TM)

3 Email addresses: tsutomu.kuboyama.a@vc.ibaraki.ac.jp (TK) 


\section{Abstract}

Lotus root (Nelumbo nucifera) is an edible rhizome that the consumption/production has continuously increased as more consumers demand convenient and ready-to-eat foods. However, the processing, storage, and transportation of fresh-cut fruits and vegetables promotes physiological deterioration, such as browning, which leads to a reduction in the value of the product. This study aimed to reduce the browning of lotus root pericarps during long-term storage and long-distance transport, and to clarify the functions of unigenes and browningassociated metabolic pathways using RNA-sequencing techniques. Intact lotus root cv. 'Kanasumi No.34' browning decreased after the roots were packed along with an anti-browning solution. Over 200 million short single-end reads were mapped onto the $N$. nucifera consensus coding sequence set. The significantly differentially expressed genes (DEGs) were identified. Based on the Uniprot, GO, and KEGG databases, secondary metabolism, lipid metabolism, and redox state genes were significantly upregulated in the un-packed (UP) and packed with water (PW) treatments compared to after harvest (AH) sample. Additionally, 16 expected differentially expressed genes (e.g., $P P O, P A L, P O D, C H S, P D C R$, and $S O D$ ), which are affected by browning development, were differentially regulated in lotus root pericarp. The gene expression data presented in this study will help elucidate the molecular mechanism underlying browning development in intact lotus root during long-term storage. The results may also inform future research on improving the post-harvest life of lotus roots. 


\section{Introduction}

Lotus root (Nelumbo nucifera), an edible rhizome, is a popular vegetable across the globe because of its attractive white color, abundant nutrients, and crispness. In recent years, fresh cut lotus root has been attracting increasing research and industry interest as it could potentially be a novel, minimally processed vegetable. However, it is well known that the enzymatic browning of fruits and vegetables is a consequence of mechanical and physical stresses that occur during post-harvest handling, processing, storage, and transportation. These stresses promote physiological deterioration, which reduces the value of the product. Browning is the most important problem to affect lotus root during processing and storage, and the resultant deterioration has limited the development of the lotus root industry (Jiang et al. 2014)

Most anti-browning systems extend the shelf life and improve the quality of postharvest fruits and vegetables by including chemical and physical methods that inhibit polyphenol oxidase (PPO) activity. They tend to focus on the essential components of reactions, such as oxygen, copper ions, and substrates (Queiroz 2008). Thermal technology and other effective measures, including low temperature, modified atmosphere packaging, irradiation, and coating, have been applied (Ioannou and Ghoul 2013; Tinello and Lante 2018). These methods prevent moisture and aroma loss and inhibit oxygen penetration into the plant tissue. For example, in a preliminary experiment, lotus roots were harvested and stored at $5^{\circ} \mathrm{C}$ for 10 days to reduce development of the browning color during storage. There are numerous compounds and physical methods capable of reducing enzymatic browning, which suggests that it should be possible to use natural anti-browning agents during processing and storage. Currently, synthetic additives and natural substances that are eco-friendly, inexpensive, safe for human health, and contain several bioactive compounds have been used as anti-browning agents to reduce color change. Onions contain bioactive compounds, such as flavonoids, alkaloids, phenolic acids, coumarins, and essential oils (Amin 2005; Eissa et al. 2006; Tattelman 2005) and onion extract can inhibit enzymatic browning in mushrooms, bananas, and pears (Bernaś and Jaworska 2015; Kim et al. 2005; Lee 2007). The effect of 36 plant extracts on the inhibition of enzyme browning in fresh-cut apple was investigated by (Wessels et al. 1995).

The mechanism regulating the browning of fruits and vegetables has been investigated for several decades. Enzymatic browning of fruits and vegetables is initiated by PPO, which is a major induction (Martinez and Whitaker 1995; Lante et al. 2016). The complex processes controlling enzymatic browning also involve many other enzymes that induce or inhibit enzymatic browning, such as peroxidase (POD), phenylalanine ammonia lyase (PAL), superoxide dismutase (SOD), and catalase (CAT) (And and Watson 2016; Degl'Innocenti et al. 2007; 
Droillard et al. 1987). The PAL, PPO, and POD enzymes have been shown to cause tissue browning in many species, such as apples, pineapples, sweet potato, pears, and cabbage (Murata et al. 2001; Zhou et al. 2003; Liao et al. 2006; Yan et al. 2013; Cheng et al. 2015; Banerjee et al. 2015). Sun et al. (2015) found that PPO and POD activities in fresh-cut lotus root slices were significantly inhibited after treatment with $\mathrm{H}_{2} \mathrm{~S}$. Similar changes in POD activities have also been observed during lotus root cv. 3537 browning, and browning degree was significantly positively correlated with POD activity during storage (Jiang et al. 2014). Enzymatic oxidation of phenolics, membrane lipid peroxidation, reactive oxygen species (ROS) overproduction, and scavenger system failure have been shown to be responsible for the browning process in lotus root slices (Sun et al. 2015; Zhang et al. 2013). However, the molecular mechanisms underlying PPO, PAL, and POD involvement with intact lotus root browning during long-term storage is poorly understood.

A number of studies have used RNA sequencing (RNA-seq) to investigate the transcriptomes related to fresh cut lotus (Mellidou et al. 2014; Zhu et al. 2017) and rhizome formation by the plant (Yang et al. 2015). However, there is still little information available about the mechanisms underlying the browning of intact lotus roots during long-term storage. High-throughput transcriptome sequencing technology has recently been widely used to analyze the gene expression levels of whole organisms. The overall comprehensive characteristics of the root transcriptome from lotus were determined using the Illumina NovaSeq 6000 platform, which identified the genes and pathways involved in the browning mechanism. In this study, high-throughput sequencing technology was used to examine gene expression profiles in intact lotus root peels. We analyzed the unigene functions and the browning-associated metabolic pathways were annotated and classified.

\section{Materials and Methods}

\section{Plant growth and sampling}

Lotus roots from 'Kanasumi no. 34' (short shape) were harvested from a lotus farm in Ibaraki Prefecture during August 2018. They were then transported to the laboratory and the roots to be used in the experiment were selected based on uniformity of size, ground color, and freedom from defects. They were washed with tap water to remove any soil that was still attached after cutting and transferred to a pack solution. Three replicate of each treatments were; after harvest samples (AH), Unpackaged (UP), Packed without water (PNW), Packed with Water (PW), Packed with $0.1 \%$ ascorbic acid solution (PAA), Packed with $1 \%$ onion solution (PO), and Packed with $0.1 \%$ citrus peel solution (PC). These samples were then kept in a refrigerator at $5^{\circ} \mathrm{C}$ and $60 \%-80 \%$ relative 
humidity for 0 hr., 6 hr., 10 days, 20 days, and 30 days. The lotus peel was collected after storage and kept at $80^{\circ} \mathrm{C}$ until needed. The color was assessed after storage in all treatments. The functions of the unigenes and browning-associated metabolic pathways were clarified using RNA-sequencing techniques to analyze the intact lotus root peels from three replicate of UP and PW after $6 \mathrm{hr}$. Then the results were compared with the AH results (S1 Fig.). The key-browning-related genes in all the treatments were investigated by qRT-PCR analysis.

\section{RNA isolation}

Samples $(1 \mathrm{~g})$ of frozen lotus root peel were ground in liquid nitrogen to a fine powder and the total RNA was extracted using the hot-borate method (Wan and Wilkins 2011). There were three replicates of the lotus tissue extracts. The RNA integrity was evaluated using 1.0\% agarose gel stained with GelStar® Nucleic Acid Gel Stain. Total RNA was quantified and examined for protein contamination $\left(\mathrm{A}_{260} / \mathrm{A}_{280}\right)$ and reagent contamination $\left(\mathrm{A}_{260} / \mathrm{A}_{230}\right)$ using a NanoDrop ND-1000 spectrophotometer. The high-quality total RNA samples had two distinct peaks and well defined-yield levels.

\section{Library preparation and Illumina sequencing}

Beijing Novogene Bioinformatics Technology Co., Ltd (China) was responsible for cDNA library construction and Illumina sequencing. The first step in the cDNA library construction process was to briefly enrich the lotus tissue using oligo (dT) beads. Then, the mRNA was randomly fragmented by adding a fragmentation buffer, and cDNA was synthesized using an mRNA template and a random hexamers primer. Next, a custom second-strand synthesis buffer (Illumina), dNTPs, RNase H, and DNA polymerase I were added to initiate secondstrand synthesis. The double-stranded cDNA library was completed after a series of terminal repairs, A ligation, sequencing adapter ligation, size selection, and PCR enrichment. The qualified libraries were fed into Illumina sequencers after pooling according to their effective concentration and expected data volume.

\section{Bioinformatics analysis}

\section{Pre-processing of the raw read sequences}

The RNA-Seq pipeline in this study is shown in Figure 1 The raw reads were processed by Beijing Novogene Bioinformatics Technology Co., Ltd. (China). Quality control for the raw reads was performed using FastQC, and high-quality reads were obtained after adapter trimming by Cutadapt (Martin 2011). The trimmed 
133

reads had both of 5'-and 3'-ends, but those with low quality ends, (quality scores $<30$ ), and reads where $\mathrm{N}>10 \%$

(N represents bases that cannot be determined) were removed. Finally, reads containing low quality (Qscore $\leq 5)$ bases, which accounted for over $50 \%$ of the total bases, were removed. All downstream analyses were based on high-quality clean reads. The subsequent analyses were performed on high-quality clean read datasets whose quality had been confirmed by the bioinformatics analysis.

138

139

Cafflinks. Only unique mappings were used in the expression analyses.

(version 2.3.0; 2) and annotating them against an NCBI Nr protein database (NCBI non-redundant sequence

DEGs were mapped onto the (http://www.kegg.jp/blastkoala/) (Kanehisa et al. 2016). Then, GO annotation of the transcriptome was performed 153 samples using a PrimeScript ${ }^{\mathrm{TM}}$ RT reagent kit containing gDNA Eraser (Shiga, Japan). The cDNA was stored at $80^{\circ} \mathrm{C}$ until needed for the qRT-PCR analysis. In the qRT-PCR assay, cDNA was treated with SYBR ${ }^{\circledR}$ Premix Ex

\section{Data processing and differential gene expression analysis}

The high-quality clean reads were mapped against the Nelumbo nucifera_V1.1 reference genome sequence (https://www.ncbi.nlm.nih.gov/Traces/wgs/APLB01/) using the TopHat program. The tolerance parameters were the default settings, and transcripts were identified from the TopHat alignment results using

\section{Functional annotation} database, a subset of Viridiplantae). BLASTX further aligned consensus sequences to a number of protein databases, such as Swiss-Prot (Bairoch and Boeckmann 1991) and TrEMBL (Bairoch and Apweiler 2000). The (Zdobnov and Apweiler 2001).

\section{Reverse transcription real-time quantitative PCR (qRT-PCR)}

A qRT-PCR analysis was performed to validate the mRNA abundance of 16 genes that were significantly related to browning. Total RNA was isolated from lotus root peel and cDNAs were generated from the RNA $\mathrm{Taq}^{\mathrm{TM}}$ II (Takara, Japan) according to the manufacturer's protocol and analyzed using an Illumina $\mathrm{Eco}^{\mathrm{TM}} 48$ Real Time PCR system in a total volume of $10 \mu \mathrm{L}$. The PCR cycle comprised one 15 s cycle at $95^{\circ} \mathrm{C}$, followed by 40 cycles at $94^{\circ} \mathrm{C}$ for $15 \mathrm{~s}, 60^{\circ} \mathrm{C}$ for $30 \mathrm{~s}$, and $72^{\circ} \mathrm{C}$ for $30 \mathrm{~s}$. All amplified products were subjected to a melt curve 
162

163

164

165

166

167

168

169

170

171

172

173

174

175

176

177

178

\section{Results}

180

181

182

183

184

185

186

187

188

189

190

analysis. A negative control without a cDNA template was used in all the analyses to evaluate the overall specificity. The beta-actin reference gene was used to normalize the total amount of cDNA in each reaction. Amplification efficiency and relative gene expression levels were calculated using the $\Delta \Delta C_{\mathrm{T}}$ and $2^{-\Delta \Delta C}$ Tethods $\left(C_{\mathrm{T}}\right.$; cycle threshold), and the $\Delta C_{\mathrm{T}}$ value of each gene was calculated by subtracting the $C_{\mathrm{T}}$ value of the endogenous control from the $C_{\mathrm{T}}$ value of the target gene. The gene-specific primers were designed using primer3plus (Untergasser et al. 2007) (Table S2).

\section{Availability of supporting data}

The data sets supporting the results produced by this study are available in the DDBJ Sequence Read Archive (DRA) (accession number PRJDB8707).

\section{Statistical analysis}

Significant changes in gene expression by qRT-PCR, height and gene expression between different treatments were evaluated by one-way analysis of variance (ANOVA) using a software package (StatView Ver.5.0, SAS Institute Inc. Cary, NC, USA). Multiple Range Tests were performed, using the Tukey`s HSD with a confidence level of $95 \%$.

\section{Effects of anti-browning solutions on lotus root browning}

Development of browning was analyzed by measuring the $L^{*}, a^{*}$, and $b^{*}$ values. The browning effect decreased when the packets contained an anti-browning solution. Only the $L^{*}$ value has been reported in this paper because it represents lightness and is negatively correlated with browning intensity. The $L^{*}$ value change ratio for 'Kanasumi no.34' tended to increase for all treatments after long-term storage (Fig. 2A). The $L^{*}$ values change ratio for UP increased rapidly after storage and was significantly different from the other treatments $(P<0.05)$. Furthermore, PNW and the anti-browning solution treatments maintained higher $L^{*}$ values that had low $L^{*}$ changing ratio. This showed that they effectively inhibited browning after long-term storage. The Total soluble solids (TSS) contents had decreased by the end of the storage period in the treatments that involved packaging and were significantly different from the control (Fig. S3). The appearance of the lotus roots after storage is shown in Fig. 3 and the sensory test results showed that the PAA, PO, and PC treatments had the highest color scores 
191

192

193 respectively (data not showed).

\section{Overview of the sequencing reads}

acceptant. Furthermore, the smell acceptance scores were significantly lower in the PO and PC groups, but the overall PW and PAA acceptance scores were significantly higher than AH (Fig. S3). The expression patterns for the genes involved in lotus root peel browning development during the initial storage stage were determined by analyzing the RNA extracted from peel after harvest (AH) and in the UP, and PW treatments after 6 hr. of storage.

The RNA was extracted from the peel taken after harvest (AH), and from the UP and PW treatments after $6 \mathrm{hr}$. of storage. It was then sequenced using the Illumina NovaSeq 6000 platform and an overview of the sequencing is outlined in Table S4. The Q20, Q30, and GC content were calculated using the clean data and are also shown in Table S4. After the adapter sequences and low-quality reads had been removed, there was an average of $23,268,137,22,204,886$, and 20,655,196 high-quality clean reads for AH, UP, and PW, respectively. Over 90\% of the clean reads had Phred-like quality scores at the Q30 level, and the average GC content of these samples was 46.28\% (Table S4). High-quality transcriptome sequence reads were preprocessed for further analysis.

\section{Differentially expressed gene analysis}

We compared and identified differentially expressed genes among the AH, UP, and PW data. Normalization was applied to the treatments to provide accurate differential expressions rather than individual quantifications. A total of 33,656, 31,674, and 32,587 unigenes were annotated from the AH $v s$ UP, AH vs PW, and UP vs PW libraries, respectively (data not showed). The significant DEGs with FDR values $<0.01$ and a one $\log 2$ fold change were obtained by comparing the AH vs. UP, AH vs PW, and UP vs PW libraries. There were 2,091 2,188, and 1,103 DEGs, respectively, (data not showed). The DEG distributions were further annotated using the database. DEGs were first searched against the Swiss Institute of Bioinformatics databases (Swiss-Prot) by local BLASTX (E-value cutoff was set at 1e-5) to search for the maximum number of similar genes. There were 1,177, 1,164, and 624 up and downregulated genes among the AH vs UP, AH vs PW, and UP vs PW libraries,

\section{Functional classification by GO distribution and GO enrichment}


220 (Fig. 4). Several significantly induced GO terms representing molecular functions were associated with protein

221 binding, DNA binding, and ATP binding (Fig. 4A). The biological process that was significantly enriched in the

222 set of induced DEGs across all treatments was the oxidation-reduction process (Fig. 4B). Other over-represented

223 biological processes included metabolic processes, regulation of transcription, and protein phosphorylation. A

224 significant number of DEGs were also related to the transmembrane transport, signal transduction, and

225 carbohydrate metabolic processes (Fig. 4B). In the cellular component category, the most significant DEGs were

226 associated with membrane and integral components of the membrane (Fig. 4C). When the significant DEGs were

227 subjected to GO enrichment analysis, most of them were significantly represented in the three main GO categories

228 of 'biological process' (BP), 'molecular function' (MF), and 'cell component' (CC). Nucleic acid binding (in the

229 MF category), RNA-DNA hybrid ribonuclease activity (MF), and DNA integration (BP) were significantly

230 enriched when UP was compared with AH (Fig. 5). The RNA-DNA hybrid ribonuclease activity (MF),

231 proteinaceous extracellular matrix (CC), and sodium ion export (BP) were the most highly enriched terms in the

232 AH vs PW library (Fig. 5). Furthermore, aspartic-type endopeptidase activity (MF), DNA integration (BP), and

233 sequence-specific DNA binding transcription factor activity (MF) were significantly enriched when UP was

234 compared with PW (Fig. 5). The overall distribution of GO enrichment in this study is summarized in Table S5.

235

236 KEGG enrichment of differentially expressed genes

237 The KEGG pathway database records networks of molecular interactions in cells and their variants are

238 specific to particular organisms. Pathway-based analysis helps us to understand the biological functions of gene

239 products. The pathway information for all annotated sequences was obtained from the KEGG pathway annotations.

240 In total, 14,977 protein (Peps) in AH vs. UP, 14,938 in AH vs PW, and 9,911 in UP vs PW were mapped to the

241 reference pathway in KEGG using the BLAST KOALA program. The genetic information processing and

242 environmental information processing subcategories in the functional protein family category were significantly

243 enriched in this study. Other functional categories included carbohydrate metabolism, biosynthesis of other

244 secondary metabolites, and lipid metabolism (Fig. S7). The KEGG Orthology (KO) list is summarized in Table

245 S6. In this study, we focused on the phenylpropanoid biosynthesis pathway, tyrosine metabolism, lipid metabolism,

246 and the peroxisome pathway (Fig. S7). Phenylalanine ammonia-lyase (EC:4.3.1.24), caffeoylshikimate esterase

247 (EC:3.1.1), shikimate O-hydroxycinnamoyltransferase (EC:2.3.1.133), cinnamyl-alcohol dehydrogenase

248 (EC:1.1.1.195), peroxidase (EC:1.11.1.7), and caffeic acid 3-O-methyltransferase (EC:2.1.1.68) were significantly 
249

250

251

252

253

upregulated in the phenylpropanoid biosynthesis pathway (Fig. S7). The results also showed that primary-amine oxidase (EC:1.4.3.21), aromatic-L-amino-acid/L-tryptophan decarboxylase (EC:4.1.1.28 4.1.1.105), polyphenol oxidase (EC:1.10.3.1), and primary-amine oxidase (EC:1.4.3.21) were upregulated in the tyrosine metabolism pathway (Fig. S7). In particular, the polyphenol oxidase (EC:1.10.3.1) group is known to contain enzymes that play important roles in the browning mechanism. Furthermore, acyl-CoA oxidase (EC:1.3.3.6), 3-hydroxyacylCoA dehydrogenase (EC:5.3.3.8), and long-chain fatty acid omega-monooxygenase (EC:1.14.14.80) were upregulated in the lipid degradation metabolism pathway, and superoxide dismutase (EC:1.15.1.1) in the peroxisome metabolism pathway was the most significantly upregulated enzyme (Fig. S7).

\section{Candidate genes involved in intact lotus root browning}

This study, based on the Swiss-Prot, GO databases, and the KEGG pathway searches, focused on pathways expected to be involved or influenced by browning development during long-term storage of lotus roots, such as secondary metabolism (SM) (fourteen transcripts), lipid metabolism (four transcripts), and redox state (three transcripts) (Table 1).

\section{Validation of differentially expressed genes based on a RNA-seq data analysis by quantitative real-time PCR}

The results from the transcriptome analysis were validated by selecting 16 differentially expressed genes that were expected to be involved or influenced by browning development and summarizing them in a heatmap (Fig. 6). These DEGs were associated with secondary metabolism, tyrosine metabolism, lipid metabolism, and redox state. A qRT-PCR analysis of the selected genes was performed (Fig. 7). The eventual brown discoloration is usually the result of interactions between PPO activity and polyphenol content. The PPO (XLOC_018282) gene accumulated during browning and its expression levels were higher in all the treatments compared to $\mathrm{AH}$ (the control). Although PPO (XLOC_018282) expression was highest in PAA and PO after $6 \mathrm{~h}$, the expression levels in these treatments were still relatively low after 30 days (Fig. 7A). In contrast, the PPO (XLOC_017349) gene increased sharply after long-term storage, which indicated that the anti-browning solutions did not significantly reduce the expression of this gene (Fig. 7B). POD (XLOC_015548) expression increased after storage, especially after 30 days in UP and PC (Fig.7C). Furthermore, PAL (XLOC_012978) expression, the key gene in the initial step of the phenylpropanoid pathway, was significantly higher in UP after 30 days of storage (Fig. 7D). However, 4CLL9 (XLOC_008727) levels remained constant in all treatments except PW where it was significantly higher 
278 after 6-h of storage. (Fig. 6E). CHS1 (XLOC_014927), an important gene in the flavonoid and anthocyanin 279 biosynthesis pathway, increased after long-term storage in all treatments except UP where it declined (Fig. 7F). The lignin biosynthesis genes included HST (XLOC_004699), CSE (XLOC_026573), and COMT (XLOC_011410). HST expression was highest after the lotus root had been being packed with water (PW) and stored for $6 \mathrm{~h}$, whereas its levels were lowest after 30 days in UP (Fig. 7G). The CSE and COMT genes showed similar patterns because they also decreased after storage in all treatments, apart from UP after 30 days where their expressions were higher (Fig. 7H). In addition, SCPL50 (XLOC_026371) expression decreased after long-term storage in all treatments (Fig. 7J). The expressions of the lipid metabolism related genes TOGT1 (XLOC_000017), CUT1 (XLOC_000169), and HOS3 (XLOC_001264) tended to decrease after long-term storage in all treatments. However, the UP treatment showed the lowest level after 30-days (Figs. $7 \mathrm{~K}-\mathrm{M})$, which was the opposite of PDCR (XLOC_021293). The lipid degradation gene increased after long-term storage, especially in UP after 30 days, which showed the greatest upregulation (Fig. 7N). In addition, the redox state-related gene, FMO (XLOC_005442), tended to decrease after long-term storage, but its levels were high in UP after 30 days. This contrasted with $S O D$ (XLOC_005179), which increased in PNW and PC after storage. The increase mainly occurred after 30 days (Figs. $7 \mathrm{O}, \mathrm{P})$.

\section{Discussion}

\section{Effect of anti-browning solutions on the discoloration of intact lotus root}

Intact lotus roots during long-term storage and long-distance transport require optimal post-harvest treatments to slow down physiological disorders, such as browning on the skin. In this study, the browning of intact lotus roots during long-term storage was reduced by packing them with different anti-browning solutions (PW, PAA, PO, and PC). The anti-browning solution treatments had higher $L^{*}$ values, color scores, and overall acceptance values than the storage treatment control (UP). Browning is an oxidative reaction, which means that it can be reduced by removing oxygen from the surface of the root, although browning will rapidly occur when oxygen is reintroduced. Oxygen can be removed by immersing the roots in deoxygenated water, and washing away any leached phenolics and enzymes from the surface can also improve the deoxygenation process (McEvily et al. 1992). In this study, lotus roots that had been vacuum packed without water (PNW) or packed with deoxygenated water (PW) showed delayed browning development after 30 days. It has also been reported that reducing 
307

308

309

310

311

312

313

314

315

316

317

318

319

320

321

322

323

324

325

326

327

328

329

330

331

332

333

334

335

dihydroxyphenols or by irreversible inactivation of PPO (Osuga and Whitaker 1995; Rojas-Graü et al. 2006; Tortoe et al. 2007). Similarly, Sun et al., (2010) also reported that AA had an anti-browning effect on fresh-cut apples. Onion has been found to have bioactive compounds that can reduce enzymatic browning and/or oxidoreductase activity (Eissa et al. 2006). They are particularly rich in flavonoids and alk(en)yl cysteine sulfoxides (ACSO).

Sulfur compounds are also important because they strongly inhibit PPO activity (Griffiths et al. 2002; Lee 2007; Bernaś and Jaworska 2014), and citrus powder solution effectively delayed browning in this study.

Citrus peel is an anti-browning agent and is known to be rich in polyphenolic compounds. About $0.1 \%$ citrus peel extract has been shown to effectively reduce the browning of apple slices (Park and Kim 2013). In addition, mandarin orange peel extracts are a potential source of compounds that can control browning during the storage of apple slices (Chang et al. 2011). Citrus fruit peel powder also seems to effectively protect against browning development. The natural anti-browning antioxidants can prevent the initiation of browning by reacting with oxygen. They also react with intermediate products, which breaks the browning chain reaction (Lindley 1998; Wessels et al. 2014).

\section{Functional annotation and classification during browning development in intact lotus root}

Lotus roots are an economically important vegetable in Japan and are rich in nutrients and phenolic compounds. The genes involved in lotus root browning were identified by extracting the total RNA from lotus skin. Then mRNA samples were prepared and fragmented, and used to synthesize cDNA. The cDNA was sequenced using the Illumina NovaSeq 6000 platform, and the resulting sequencing data were subjected to bioinformatics analysis. The relevant genes or proteins were identified by analyzing them using the associated Uniprot database, GO term, and KEGG pathway. Enzymatic processes were generally recognized as the main determinants of browning. In addition, lipid metabolism and the activities of antioxidant enzymes were also related to browning.

The transcriptome analysis focused on the phenylpropanoid metabolic pathway, which is involved in phenolic synthesis. Phenolic synthesis is regulated by several key enzymes, including PAL, 4CL CHS, and CHI. The pathway results in the formation of polyphenols or flavonoids, which cause browning when the plant tissue is exposed to air (Cantos et al. 2002; Saltveit 2004; Suehiro et al. 2014; Alegria et al. 2016). Zhang et al. (2019) found that the PAL, C4H, 4CL, and CHS enzymes were upregulated in fresh-cut walnut. In this study, SM played a key role in protecting plants against biotic stresses. Several genes related to SM showed differential expressions 
336

337

338

339

340

341

342

343

344

345

346

347

348

349

350

351

352

353

354

355

356

357

358

359

360

361

362

363

364

when lotus root was subjected to long-term storage (e.g., those related to $P A L, P O D, 4 C L, C H S$, CSE, and COMT;

Table 1: S7), which suggested that high SM-related gene expressions promoted the activity of relevant enzymes leading to an increase in phenolic compounds derived from the phenylpropanoid pathway. This result is consistent with other studies on browning in fresh-cut fruits and vegetables (Hisaminato et al. 2014; Persic 2018; Liu et al. 2018). Furthermore, a number of lipid and membrane related DEGs identified by the GO distribution encoded key enzymes involved in fatty acid biosynthesis and the lipid degradation pathways (Table 1; Fig. 4). This confirmed that membrane lipid alterations in lotus root peels were similar to those in pears and fresh-cut apple (Saquet et al. 2003; Mellidou et al. 2014).

Pericarp browning in lotus root involves oxidation-reduction processes (Fig. 4), and antioxidant enzymes (FMO, SOD; Fig. 6) involved in the peroxisome pathway were differentially expressed. Antioxidative enzymes play a key role in scavenging reactive oxygen species (ROS) under oxidative stress conditions (Sun et al. 2010). Duan et al. (2011) reported that SOD enzymes decrease ROS-induced damage and membrane lipid peroxidation in litchi fruits (Duan 2011). Similarly, in pear and apple, SOD genes also showed significantly higher activities during browning development (Mellidou et al. 2014; Fan et al. 2016; Zhu et al. 2017).

\section{Candidate genes for browning development during long-term storage of intact lotus root}

$P P O$ and $P O D$ are considered to have important roles in the enzymatic browning of fruits and vegetables (Chi et al. 2014; Dokhanieh et al. 2016). The PPO enzyme, encoded by members of the PPO multigene family, is considered to be the major factor responsible for the enzymatic browning of several fresh-cut vegetables (Degl'Innocenti et al. 2007; Chisari et al. 2008). In this study, PPO (XLOC_018282) genes in lotus roots subjected to anti-browning solutions during long-term storage increased compared to their levels immediately after harvest (Fig. 7). However, the PPO (XLOC_018282) expressions in the PAA and PO treatments were low after 30 days of storage (Fig. 7A), which suggested that AA, a reducing compound, and onion, which contains various volatile sulfur compounds, including thiols that have been reported to inhibit PPO, effectively reduce $P P O$ expression (Negishi and Ozawa 2000; Ding et al. 2002). Similarly, Kim et al. (2005) found that pear polyphenol oxidase was also inhibited by onion extract. POD (XLOC_015548) is an enzyme that is involved in phenolic oxidation. It was upregulated in UP, but its expression was low after 30 days in the PAA and PO treatments (Fig. 7C). PAL has been reported to be involved in the browning of fresh-cut potatoes, carrots, lotus roots, and apples (Alegria et al. 2016; Wu et al. 2018; Gaoet al. 2017) and CHS is involved in grape skin browning (Suehiro 2014). Our results indicated 
365 in the redox state system during browning (Mellidou et al 2014; Zhu et al. 2016).

that the relative expression levels of PAL (XLOC_012978) genes involved in the phenylpropanoid biosynthesis pathway were most highly upregulated in UP after 30 days, but their expression levels were low in the other treatments (Fig. 7D). In addition, Zhang et al. (2019) found that the CHS gene and two $4 C L$ genes were significantly differentially expressed in browned walnut husks. Chalcone synthase (CHS) plays a key role in flavonoid and anthocyanin biosynthesis. In our study, lotus roots packed without oxygen (PNW) and those packed with anti-browning solution maintained their CHS1 (XLOC_014927) expression levels, but CHS1 expression was low in UP after 30 days (Fig. 7F). In contrast to the caffeoylshikimate esterase (CSE) and caffeic acid 3-Omethyltransferase (COMT) genes, the important genes in the lignin biosynthesis pathway showed low expression levels after long-term storage in anti-browning solution, but were highly upregulated after 30 days in the UP treatment (Figs. 7H, I). Coumaric, caffeic, and ferulic acids, coniferaldehyde, and coniferyl alcohol (precursors in lignin synthesis) proved to be good substrates for POD during the browning of cut jicama (Aquino-Bolaños and Mercado-Silva 2004). Our results suggested that lotus root browning may be related to the lignification process. During long-term storage, fruits or vegetables need mechanisms that allow them to tolerate oxidative stress and maintain membrane integrity. After the long-term storage of lotus root, the anti-browning solution treatments, especially PAA and PO, maintained 3-ketoacyl-CoA synthase (KCS or CUT1) expression levels, whereas the UP treatment had the lowest expression levels for these enzymes (Fig. 7L). In general, very-longchain fatty acids (VLCFAs) are essential precursors of cuticular waxes and aliphatic suberin in roots. The VLCFAS are synthesized by a fatty acid elongation system on the endoplasmic reticulum membrane, and KCS is an enzyme in the initial and rate-limiting step. This suggests that 3-ketoacyl-CoA synthase and elongation of fatty acid protein 3-like enzymes may be involved in lotus root browning. However, peroxisomal 2,4-dienoyl-CoA reductase (PDCR), a key enzyme in lipid degradation, was the most upregulated in UP after 30 days (Fig. 7P). Furthermore, VLCFA synthesis genes and lipid degradation genes were significantly upregulated in fresh-cut apple (Mellidou et al 2014). Fan et al. (2016) reported that significantly higher activities of antioxidant enzymes (i.e., SOD) were maintained in 'Laiyang' pear fruits undergoing browning (Fan et al. 2016). Superoxide dismutase is an important antioxidant enzyme that catalyzes the dismutation of superoxide to $\mathrm{O}_{2}$ and $\mathrm{H}_{2} \mathrm{O}_{2}$. In this study, SOD expression increased when lotus root was treated with an anti-browning solution and this may be because SOD reduces ROS 


\section{Conclusion}

The lotus root is an economically important vegetable in Japan and is rich in nutrients and phenolic compounds.

Therefore, it is important to find post-harvest treatments that slow down the browning of intact lotus root pericarps during long-term storage and long-distance transport. In this study, the browning of intact lotus root was reduced by packing them with an anti-browning solution (PAA, PO, and PC; Fig. 8). The genes involved in lotus root browning were identified by comparing the AH, UP, and PW transcriptomes after $6 \mathrm{~h}$. storage at low temperature. Significant DEGs were obtained by comparing the AH $v s \mathrm{UP}, \mathrm{AH} v s \mathrm{PW}$, and UP $v s$ PW libraries, which contained 2,091 2,188, and 1,103 DEGs, respectively. Furthermore, SM, lipid metabolism, and redox state-related genes were significantly upregulated according to the results based on the UniProt database, GO databases, and KEGG pathway, especially in unpackage (UP) treatment (Fig. 8). Additionally, 16 genes that were expected to be differentially expressed (e.g., $P P O, P A L, P O D, C H S, P D C R$, and $S O D$ ) and are influenced by browning development were differentially regulated in lotus root pericarp. The genetic resources and putative signaling pathways related to lotus root defense responses against browning may be useful in future molecular studies on Nelumbo nucifera.

\section{References}

Alegria C, Gonçalves EM, Moldão-Martins M, Cisneros-Zevallos L, Abreu M (2016) Peel removal improves quality without antioxidant loss, through wound-induced phenolic biosynthesis in shredded carrot. Postharvest Biology and Technology 120:232-239. doi:10.1016/j.postharvbio.2016.07.004

Amin M, Kapadnis, BP (2005) Heat stable antimicrobial activity of Allium ascalonicum against bacteria and fungi. Indian J Exp Biol 43:751-754.

And OL, Watson MA (2001) Effects of ascorbic acid on peroxidase and polyphenoloxidase activities in fresh-cut cantaloupe melon. Journal of Food Science 66(9):1283-6. doi.org/10.1111/j.1365-2621.2001.tb15202.x

Aquino-Bolaños EN, Mercado-Silva E (2004) Effects of polyphenol oxidase and peroxidase activity, phenolics and lignin content on the browning of cut jicama. Postharvest Biology and Technology 33(3):275-83. doi.org/10.1016/j.postharvbio.2004.03.009

Banerjee A, Suprasanna P, Variyar PS, Sharma A (2015) Gamma irradiation inhibits wound induced browning in shredded cabbage. Food Chemistry 173:38-44. doi:10.1016/j.foodchem.2014.09.166

Bairoch A, Boeckmann B (1991) The SWISS-PROT protein sequence data bank. Nucleic acids research 
423

424

425

426

427

428

429

430

431

432

433

434

435

436

437

438

439

440

441

442

443

444

445

446

447

448

449

450

451

19(Suppl):2247. doi: 10.1093/nar/19.suppl.2247

Bairoch A, Apweiler R (2000) The SWISS-PROT protein sequence database and its supplement TrEMBL in 2000. Nucleic acids research 28(1):45-8. doi.org/10.1093/nar/28.1.45

Bernaś E, Jaworska G (2015) Use of onion extract to prevent enzymatic browning of frozen Agaricus bisporus mushrooms. International Journal of Refrigeration 57:257-264. doi:10.1016/j.ijrefrig.2015.04.022

Chang MS, An SJ, Jeong MC, Kim DM, Kim GH (2011) Effects of antioxidative activities and antibrowning of extracts from onion, apple and mandarin orange peel as natural antibrowning agents. The Korean Journal of Food And Nutrition 24(3):406-13. doi.org/10.9799/ksfan.2011.24.3.406

Cantos E, Tudela JA, Gil MI, Espín JC (2002) Phenolic compounds and related enzymes are not rate-limiting in browning development of fresh-cut potatoes. Journal of agricultural and food chemistry 50(10):3015-23. doi.org/10.1021/jf0116350

Chi M, Bhagwat B, Lane WD, Tang G, Su Y, Sun R, Oomah BD, Wiersma PA, Xiang Y (2014) Reduced polyphenol oxidase gene expression and enzymatic browning in potato (Solanum tuberosum L.) with artificial microRNAs. BMC plant biology 14(1):62. doi.org/10.1186/1471-2229-14-62

Chisari M, Barbagallo RN, Spagna G (2008) Characterization and role of polyphenol oxidase and peroxidase in browning of fresh-cut melon. Journal of Agricultural and Food Chemistry 56(1):132-8. doi.org/10.1021/jf0721491

Cheng Y, Liu L, Zhao G, Shen C, Yan H, Guan J, Yang K (2015) The effects of modified atmosphere packaging on core browning and the expression patterns of PPO and PAL genes in 'Yali' pears during cold storage. LWT - Food Science and Technology 60 (2):1243-1248. doi:10.1016/j.lwt.2014.09.005

Degl'Innocenti E, Pardossi A, Tognoni F, Guidi L (2007) Physiological basis of sensitivity to enzymatic browning in 'lettuce', 'escarole' and 'rocket salad' when stored as fresh-cut products. Food Chemistry 104 (1):209215. doi:10.1016/j.foodchem.2006.11.026

Ding CK, Chachin K, Ueda Y, Wang CY (2002) Inhibition of loquat enzymatic browning by sulfhydryl compounds. Food chemistry 76(2):213-8. doi.org/10.1016/S0308-8146(01)00270-9

Dokhanieh AY, Aghdam MS, Sarcheshmeh MA (2016) Impact of postharvest hot salicylic acid treatment on aril browning and nutritional quality in fresh-cut pomegranate. Horticulture, Environment, and Biotechnology 57(4):378-84. doi.org/10.1007/s13580-016-0087-8

Droillard MJ, Paulin A, Massot JC (1987) Free radical production, catalase and superoxide dismutase activities 
and membrane integrity during senescence of petals of cut carnations (Dianthus caryophyllus). Physiologia Plantarum 71(2):197-202. doi.org/10.1111/j.1399-3054.1987.tb02867.x

Duan X, Liu T, Zhang D, Su X, Lin H, Jiang Y (2011) Effect of pure oxygen atmosphere on antioxidant enzyme and antioxidant activity of harvested litchi fruit during storage. Food Research International 44 (7):19051911. doi:10.1016/j.foodres.2010.10.027

Eissa HA, Fadel HHM, Ibrahim GE, Hassan IM, Elrashid AA (2006) Thiol containing compounds as controlling agents of enzymatic browning in some apple products. Food Research International 39 (8):855-863. doi:10.1016/j.foodres.2006.04.004

Fan M, Li W, Hu X, Sun Yn, Yu G, Zhang X (2016) Effect of micro-vacuum storage on active oxygen metabolism, internal browning and related enzyme activities in Laiyang pear (Pyrus bretschneideri Reld). LWT - Food Science and Technology 72:467-474. doi:10.1016/j.lwt.2016.05.015

Gao H, Chai H, Cheng N, Cao W (2017) Effects of 24-epibrassinolide on enzymatic browning and antioxidant activity of fresh-cut lotus root slices. Food Chemistry 217:45-51. doi:10.1016/j.foodchem.2016.08.063

Griffiths G, Trueman L, Crowther T, Thomas B, Smith B (2002) Onions e a global benefit to health. Phytother. Res., 16; $603 \mathrm{e} 615$.

Hisaminato H, Murata M, Homma S (2014) Relationship between the Enzymatic Browning and Phenylalanine Ammonia-lyase Activity of Cut Lettuce, and the Prevention of Browning by Inhibitors of Polyphenol Biosynthesis. Bioscience, Biotechnology, and Biochemistry 65 (5):1016-1021. doi:10.1271/bbb.65.1016

Ioannou I, Ghoul M (2013) Prevention of enzymatic browning in fruit and vegetables. European Scientific Journal 9:1857 - 7881. doi: 10.1021/bk-1995-0600.ch004

Jiang J, Jiang L, Luo H, Yu Z (2014) Establishment of a statistical model for browning of fresh-cut lotus root during storage. Postharvest Biology and Technology 92:164-171. doi:10.1016/j.postharvbio.2014.01.025

Kanehisa M, Sato Y, Morishima K (2016) BlastKOALA and GhostKOALA: KEGG Tools for Functional Characterization of Genome and Metagenome Sequences. Journal of Molecular Biology 428 (4):726-731. doi:10.1016/j.jmb.2015.11.006

Kim M-J, Kim CY, Park I (2005) Prevention of enzymatic browning of pear by onion extract. Food Chemistry 89 (2):181-184. doi:10.1016/j.foodchem.2004.02.018

Lante A, Tinello F, Nicoletto M (2016) UV-A light treatment for controlling enzymatic browning of fresh-cut fruits. Innovative Food Science \& Emerging Technologies 34:141-147. doi:10.1016/j.ifset.2015.12.029 
481

482

483

484

485

486

487

488

489

490

491

492

493

494

495

496

497

498

499

500

501

502

503

504

505

506

507

508

509

Lee M-K (2007) Inhibitory effect of banana polyphenol oxidase during ripening of banana by onion extract and Maillard reaction products. Food Chemistry 102 (1):146-149. doi:10.1016/j.foodchem.2006.05.012

Liao Z, Chen R, Chen M, Yang Y, Fu Y, Zhang Q, Lan X (2006) Molecular cloning and characterization of the polyphenol oxidase gene from sweetpotato. Molecular Biology 40 (6):907-913. doi:10.1134/s0026893306060094

Lindley MG (1998) The impact of food processing on antioxidants in vegetable oils, fruits and vegetables. Trends in food science \& technology 9(8-9):336-40. doi.org/10.1016/S0924-2244(98)00050-8

Liu X, Lu Y, Yang Q, Yang H, Li Y, Zhou B, Li T, Gao Y, Qiao L (2018) Cod peptides inhibit browning in freshcut potato slices: A potential anti-browning agent of random peptides for regulating food properties. Postharvest Biology and Technology 146:36-42. doi:10.1016/j.postharvbio.2018.08.001

Martin M (2011) Cutadapt removes adapter sequences from high-throughput sequencing reads. EMBnet. Journal 17(1):10-2. doi.org/10.14806/ej.17.1.200

Martinez MV, Whitaker JR (1995) The biochemistry and control of enzymatic browning. Trends in Food Science \& Technology 6(6):195-200. doi.org/10.1016/S0924-2244(00)89054-8

McEvily AJ, Iyengar R, Otwell WS (1992) Inhibition of enzymatic browning in foods and beverages. Critical Reviews in Food Science and Nutrition 32 (3):253-273. doi:10.1080/10408399209527599

Mellidou I, Buts K, Hatoum D, Ho QT, Johnston JW, Watkins CB, Schaffer RJ, Gapper NE, Giovannoni JJ, Rudell DR, Hertog ML (2014) Transcriptomic events associated with internal browning of apple during postharvest storage. BMC plant biology 14(1):328. doi.org/10.1186/s12870-014-0328-x

Murata M, Nishimura M, Murai N, Haruta M, Homma S, Itoh Y (2001) A transgenic apple callus showing reduced polyphenol oxidase activity and lower browning potential. Bioscience, biotechnology, and biochemistry 65(2):383-8. doi.org/10.1271/bbb.65.383

Negishi O, Ozawa T (2000) Inhibition of enzymatic browning and protection of sulfhydryl enzymes by thiol compounds. Phytochemistry 54(5):481-7. doi.org/10.1016/S0031-9422(00)00125-4

Osuga, DT and Whitaker JR (1995) In Enzymatic Browning and Its Prevention; Lee CY and Whitaker JR, Eds.; ACS Symposium Series 600; American Chemical Society: Washington, DC, Chapter 7

Park M, Kim G-H (2013) The Antioxidative and Antibrowning Effects of Citrus Peel Extracts on Fresh-cut Apples. Korean Journal of Food Science and Technology 45 (5):598-604. doi:10.9721/kjfst.2013.45.5.598

Persic M, Mikulic-Petkovsek M, Halbwirth H, Solar A, Veberic R, Slatnar A (2018) Red Walnut: Characterization 
of the Phenolic Profiles, Activities and Gene Expression of Selected Enzymes Related to the Phenylpropanoid Pathway in Pellicle during Walnut Development. Journal of Agricultural and Food Chemistry 66 (11):2742-2748. doi:10.1021/acs.jafc.7b05603

Queiroz C, Mendes Lopes, M.L., Fialho, E. and Valente-Mesquita, V.L. (2008) Polyphenol oxidase: characteristics and mechanisms of browning control. Food reviews international 24 (4):361-375

Rojas-Graü MA, Sobrino-López A, Soledad Tapia M, Martín-Belloso O (2006) Browning inhibition in fresh-cut 'Fuji'apple slices by natural antibrowning agents. Journal of Food Science 71(1):S59-65. doi.org/10.1111/j.1365-2621.2006.tb12407.x

Saltveit ME (2004) Effect of 1-methylcyclopropene on phenylpropanoid metabolism, the accumulation of phenolic compounds, and browning of whole and fresh-cut 'iceberg' lettuce. Postharvest Biology and Technology 34 (1):75-80. doi:10.1016/j.postharvbio.2004.05.001

Saquet AA, Streif J, Bangerth F (2003) Energy metabolism and membrane lipid alterations in relation to brown heart development in 'Conference' pears during delayed controlled atmosphere storage. Postharvest Biology and Technology 30 (2):123-132. doi:10.1016/s0925-5214(03)00099-1

Suehiro Y, Mochida K, Itamura H, Esumi T (2014) Skin Browning and Expression of PPO, STS, and CHS Genes in the Grape Berries of 'Shine Muscat'. Journal of the Japanese Society for Horticultural Science 83 (2):122-132. doi:10.2503/jjshs1.CH-095

Sun D, Liang G, Xie J, Lei X, Mo Y (2010) Improved preservation effects of litchi fruit by combining chitosan coating with ascorbic acid treatment during postharvest storage. African Journal of Biotechnology $9(22): 3272-9$.

Sun Y, Zhang W, Zeng T, Nie Q, Zhang F, Zhu L (2015) Hydrogen sulfide inhibits enzymatic browning of freshcut lotus root slices by regulating phenolic metabolism. Food Chemistry 177:376-381. doi:10.1016/j.foodchem.2015.01.065

Tattelman E (2005) Health Effects of Garlic. Am Fam Physician 72:103-106.

Tinello F, Lante A (2018) Recent advances in controlling polyphenol oxidase activity of fruit and vegetable products. Innovative Food Science \& Emerging Technologies 50:73-83. doi:10.1016/j.ifset.2018.10.008

Tortoe C, Orchard J, Beezer A (2007) Prevention of enzymatic browning of apple cylinders using different solutions. International Journal of Food Science \& Technology 42 (12):1475-1481. doi:10.1111/j.13652621.2006.01367.x 
539

540

541

542

543

544

545

546

547

548

549

550

551

552

553

554

555

556

557

558

559

560

561

562

563

564

565

566

567

Untergasser A, Nijveen H, Rao X, Bisseling T, Geurts R, Leunissen JAM (2007) Primer3Plus, an enhanced web interface to Primer3. Nucleic Acids Research 35 (Web Server):W71-W74. doi:10.1093/nar/gkm306

Wan CY, Wilkins TA (1994) A modified hot borate method significantly enhances the yield of high-quality RNA from cotton (Gossypium hirsutum L.). Analytical biochemistry 223(1):7-12. doi.org/10.1006/abio.1994.1538

Wessels B, Schulze-Kaysers N, Damm S, Kunz B (2014) Effect of selected plant extracts on the inhibition of enzymatic browning in fresh-cut apple. Journal of Applied Botany and Food Quality 87:16-23. doi:10.5073/JABFQ.2014.087.003

Wu Y, Liu F, Yang D-G, Li W, Zhou X-J, Pei X-Y, Liu Y-G, He K-L, Zhang W-S, Ren Z-Y, Zhou K-H, Ma X-F, Li Z-H (2018) Comparative Chloroplast Genomics of Gossypium Species: Insights Into Repeat Sequence Variations and Phylogeny. Frontiers in Plant Science 9. doi:10.3389/fpls.2018.00376

Yan S, Li L, He L, Liang L, Li X (2013) Maturity and cooling rate affects browning, polyphenol oxidase activity and gene expression of 'Yali' pears during storage. Postharvest Biology and Technology 85:39-44. doi:10.1016/j.postharvbio.2013.04.016

Yang M, Zhu L, Pan C, Xu L, Liu Y, Ke W, Yang P (2015) Transcriptomic Analysis of the Regulation of Rhizome Formation in Temperate and Tropical Lotus (Nelumbo nucifera). Scientific Reports 5 (1). doi:10.1038/srep13059

Zdobnov EM, Apweiler R (2001) InterProScan-an integration platform for the signature-recognition methods in InterPro. Bioinformatics 17(9):847-8. doi.org/10.1093/bioinformatics/17.9.847

Zhang S, Tian L, Zhang Y, Zhao H, Zhao J, Guo J, Zhu G-P (2019) De novo transcriptome assembly of the freshcut white husk of Juglans cathayensis Dode: Insights for enzymatic browning mechanism of fresh-cut husk of walnut. Scientia Horticulturae 257. doi:10.1016/j.scienta.2019.108654

Zhang S, Yu Y, Xiao C, Wang X, Tian Y (2013) Effect of carbon monoxide on browning of fresh-cut lotus root slice in relation to phenolic metabolism. LWT - Food Science and Technology 53 (2):555-559. doi:10.1016/j.lwt.2013.04.001

Zhou Y, Dahler JM, Underhill SJ, Wills RB (2003) Enzymes associated with blackheart development in pineapple fruit. Food Chemistry 80(4):565-72. doi.org/10.1016/S0308-8146(02)00375-8

Zhu H, Liu J, Wen Q, Chen M, Wang B, Zhang Q, Xue Z (2017) De novo sequencing and analysis of the transcriptome during the browning of fresh-cut Luffa cylindrica'Fusi-3'fruits. Plos one. 12(11):e0187117. 


\section{Acknowledgement}

The authors would like to thank Ibaraki University, and grants from the NARO Bio-oriented Technology

572 Research Advancement Institution (the special scheme project on regional developing strategy) for supporting

573 throughout this work. Thanks to Dr. Deden Derajat Matra for guidance about bioinformatic analysis. Thanks for

574 Editage service for editing English language.

575

\section{Supporting information}

577 S1 Fig. Lotus root picture for RNA-seq.

578 S2 Table. Genes and primers for validation of RNA-Seq results by qRT-PCR.

579 S3 Fig. Sensory test score of lotus root cv. 'Kanasumi no $34^{`}$ after long term storage at $5{ }^{\circ} \mathrm{C}, \mathrm{RH} 70-80 \%$ in 580 effective anti-browning solution (UP unpacked, PNW Packed without water, PW Packed with water, PAA packed

581 with ascorbic acid, PO packed with onion, PC packed with citrus powder.

582 S4 Fig. Overview of the sequencing reads of libraries.

583 S5 Table. GO enrichment in pericarp of lotus root were compared between AH_vs_UP, AH_vs_PW and 584 UP_vs_PW

585 S6 Table. Statistics of KEGG enrichment (KO-list)

586 S7 Fig. KEGG pathway of browning related proteins 
Figure 1 RNA-Seq Pipeline for Lotus root 'Kanasumi no.34'

589 Figure 2. The color changing ratio of $L^{*}$ value after storage 0 -hr., 6 -hr., 10,20 , and 30 days at $5{ }^{\circ} \mathrm{C}, \mathrm{RH} 70-80 \%$ 590 for 'Kanasumi no. 34'. (UP; unpacked, PNW; Packed no-air and no-water, PW; Packed with water, PAA; packed 591 with $0.1 \%$ ascorbic acid solution, PO; packed with $1 \%$ onion solution, PC; packed with $0.1 \%$ citrus powder 592 solution). *, ** indicate the significant difference between weeks, based on an ANOVA and Multiple Range Test 593 procedures with a confidence level of $95 \%$.

594 Figure 3. The appearance of lotus root after storage 0 -hr., 6-hr., 10, 20, and 30 days at $5{ }^{\circ} \mathrm{C}, \mathrm{RH} 70-80 \%$ for 595 'Kanasumi no. 34'. (UP; unpacked, PNW; Packed no-air and no-water, PW; Packed with water, PAA; packed with $5960.1 \%$ ascorbic acid solution, PO; packed with $1 \%$ onion solution, PC; packed with $0.1 \%$ citrus powder solution).

597 Figure 4. The histograms were showing GO functional analysis. The $y$-axis indicates the names of the most 598 abundant classes in each of the three main GO categories. The $x$-axis indicates the numbers of common DEGs.

599 Figure 5. The histograms were showing GO functional analysis. The $y$-axis indicates the names of the most abundant classes in each of the three main GO categories. The $x$-axis indicates $z$-score value.

601 Figure 6. Heatmap visualization of sixteen key genes associated with browning. Heatmap shows the significant 602 browning-related genes between AH, UP, and PW with $q_{-}$value $\leq 0.01$ and $\log _{2}$-fold change $\geq 1$ (red and green colors indicate up- and downregulated transcripts, respectively).

604 Figure 7. qRT-PCR analysis of selected sixteen genes after storage 0 -hr., 6-hr., 10, 20, and 30 days at $5{ }^{\circ} \mathrm{C}$, RH $60570-80 \%$ for 'Kanasumi no. 34'. (AH; After harvest, UP; unpacked, PNW; Packed no-air and no-water, PW; Packed 606 with water, PAA; packed with $0.1 \%$ ascorbic acid solution, PO; packed with $1 \%$ onion solution, PC; packed with

$6070.1 \%$ citrus powder solution). Error bars depict the standard error of the mean for three biological replicates. Non608 overlapping letters indicate significant difference between treatments, based on ANOVA analysis and Multiple 609 Range Tests procedure with a confidence level of $95 \%$.

610 Figure 8. Simple diagram of enzymatic browning (Adapted from Grotheer et al., 2005) 
Table 1. Browning-related genes induced or repressed in the intact lotus root after long term storage

613

\begin{tabular}{|c|c|c|c|c|c|c|c|c|}
\hline \multirow{2}{*}{ Lotus ID_genes } & \multirow{2}{*}{ Gene description } & \multirow{2}{*}{ Function } & \multirow[b]{2}{*}{ p_value } & \multirow[b]{2}{*}{ q_value } & \multirow[b]{2}{*}{$\log _{2} \mathrm{FC}$} & \multicolumn{3}{|c|}{ FPKM } \\
\hline & & & & & & $\mathbf{A H}$ & $\mathbf{U P}$ & PW \\
\hline \multicolumn{9}{|l|}{ Secondary metabolism } \\
\hline XLOC_004699 & $\begin{array}{l}\text { Shikimate O-hy droxy cinnamoy ltransferase } \\
\text { (HST) }\end{array}$ & $\begin{array}{l}\text { Pheny lpropanoid } \\
\text { pathway/lignin }\end{array}$ & 0.0001 & 0.0009 & -2.0002 & 0 & 4.56 & 1.14 \\
\hline XLOC_023258 & Caffeic acid 3-O-methy ltransferase & Pheny lpropanoid pathway & $5.00 \mathrm{E}-05$ & 0.0005 & 0.9652 & 0 & 29.1 & 56.82 \\
\hline XLOC_011410 & Caffeic acid 3-O-methy ltransferase (COMT) & $\begin{array}{l}\text { Pheny lpropanoid } \\
\text { pathway/lignin }\end{array}$ & 0.00105 & 0.003 & 6.8518 & 1.01 & 116.39 & 0 \\
\hline XLOC_001024 & F-box/kelch-repeat protein At1g15670 & $\begin{array}{l}\text { Phenylpropanoid metabolic } \\
\text { process }\end{array}$ & $5.00 \mathrm{E}-05$ & 0.0005 & -1.7937 & 0 & 6.61 & 1.91 \\
\hline XLOC_026371 & Serine carboxy peptidase-like 50 (SCPL) & Phenylpropanoid pathway & $5.00 \mathrm{E}-05$ & 0.0002 & -1.1862 & 17.82 & 7.83 & 0 \\
\hline XLOC_012978 & Pheny lalanine ammonia-ly ase (PAL) & Phenylpropanoid pathway & $5.00 \mathrm{E}-05$ & 0.0002 & 8.0398 & 0.7 & 182.9 & 0 \\
\hline XLOC_015548 & Peroxidase 12 (POD) & Pheny lpropanoid pathway & $5.00 \mathrm{E}-05$ & 0.0002 & 2.3765 & 4.75 & 24.66 & 0 \\
\hline XLOC_018282 & Polyphenol oxidase (PPO) & Tyrosine metabolism & $5.00 \mathrm{E}-05$ & 0.0002 & 5.7442 & 55.83 & 2992.76 & 0 \\
\hline XLOC_017349 & Polyphenol oxidase (PPO) & Tyrosine metabolism & $5.00 \mathrm{E}-05$ & 0.0002 & 6.1217 & 64.38 & 0 & 4482.9 \\
\hline XLOC_014927 & Chalcone synthase 1 (CHS) & $\begin{array}{l}\text { Phenylpropanoid } \\
\text { pathway/flavonoid }\end{array}$ & $5.00 \mathrm{E}-05$ & 0.0002 & -1.4134 & 2365.75 & 0 & 888.16 \\
\hline XLOC_008727 & 4-coumarate--CoA ligase-like 9 (4CLL) & Phenylpropanoid pathway & 0.0052 & 0.0131 & 1.4714 & 0.95 & 0 & 2.64 \\
\hline XLOC_000017 & Scopoletin glucosyltransferase (TOGT) & Glucosyltransferase metabolism & $5.00 \mathrm{E}-05$ & 0.0002 & 1.1569 & 15.46 & 34.48 & 0 \\
\hline \multicolumn{9}{|l|}{ Lipid metabolism } \\
\hline XLOC_000169 & 3-ketoacyl-CoA synthase 6 (CUT) & Fatty acid biosynthesis & $5.00 \mathrm{E}-05$ & 0.0002 & 2.9322 & 0.98 & 7.46 & 0 \\
\hline XLOC_001264 & Elongation of fatty acids protein 3-like (HOS) & Fatty acid biosynthesis & $5.00 \mathrm{E}-05$ & 0.0002 & 2.5031 & 5.27 & 29.9 & 0 \\
\hline XLOC_020194 & $\begin{array}{l}\text { Peroxisomal 2,4-dienoyl-CoA reductase } \\
\text { (PDCR) }\end{array}$ & $\begin{array}{l}\text { Lipid degradation/unsaturated } \\
\text { fatty acid beta-oxidation }\end{array}$ & $5.00 \mathrm{E}-05$ & 0.0002 & 2.1083 & 20.22 & 0 & 87.18 \\
\hline XLOC_021293 & $\begin{array}{l}\text { Peroxisomal 2,4-dienoyl-CoA reductase } \\
\text { (PDCR) }\end{array}$ & $\begin{array}{l}\text { Lipid degradation/unsaturated } \\
\text { fatty acid beta-oxidation }\end{array}$ & $5.00 \mathrm{E}-05$ & 0.0002 & 1.8965 & 11.51 & 42.86 & 0 \\
\hline \multicolumn{9}{|l|}{ Redox state } \\
\hline XLOC_005179 & Superoxide dismutase [Cu-Zn] (SOD) & Oxidation process & 0.01715 & 0.0362 & 0.5777 & 108.97 & 162.63 & 0 \\
\hline
\end{tabular}




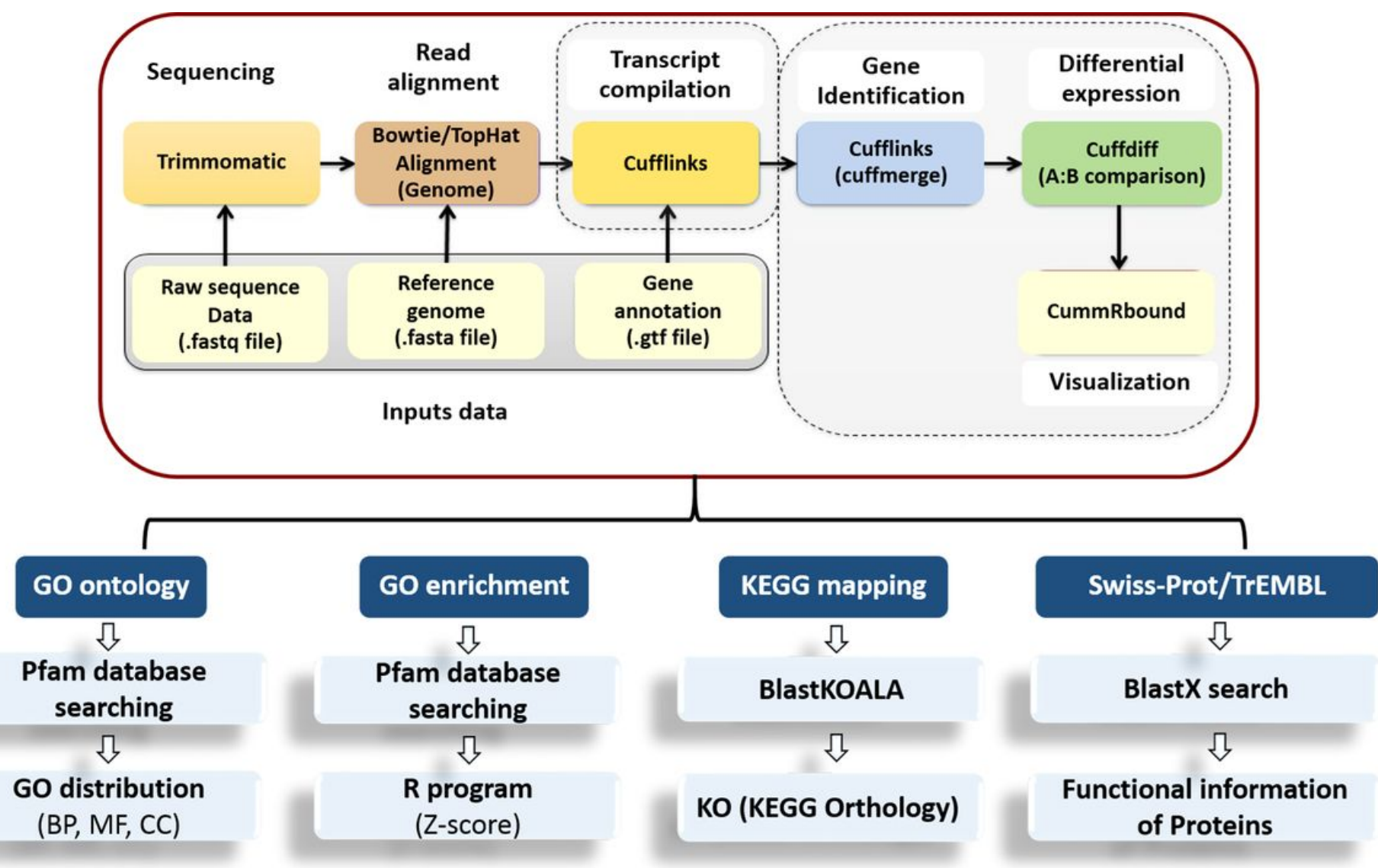

Figure 1

RNA-Seq Pipeline for Lotus root 'Kanasumi no.34'

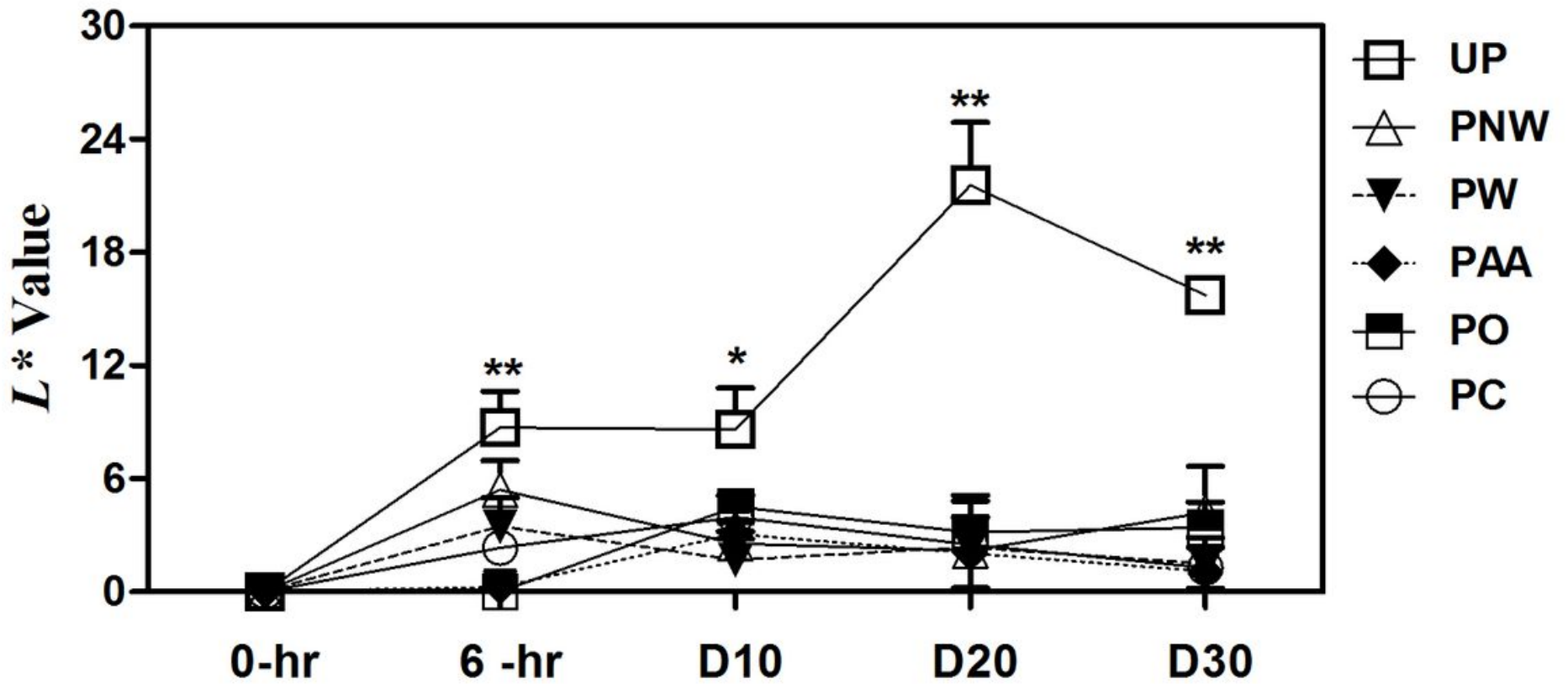




\section{Figure 2}

The color changing ratio of $L^{*}$ value after storage 0 -hr., 6 -hr., 10,20 , and 30 days at $5{ }^{\circ} \mathrm{C}, \mathrm{RH} 70-80 \%$ for 'Kanasumi no. 34'. (UP; unpacked, PNW; Packed no-air and no-water, PW; Packed with water, PAA; packed with $0.1 \%$ ascorbic acid solution, PO; packed with $1 \%$ onion solution, PC; packed with $0.1 \%$ citrus powder solution). ${ }^{*}, * *$ indicate the significant difference between weeks, based on an ANOVA and Multiple Range Test procedures with a confidence level of $95 \%$.

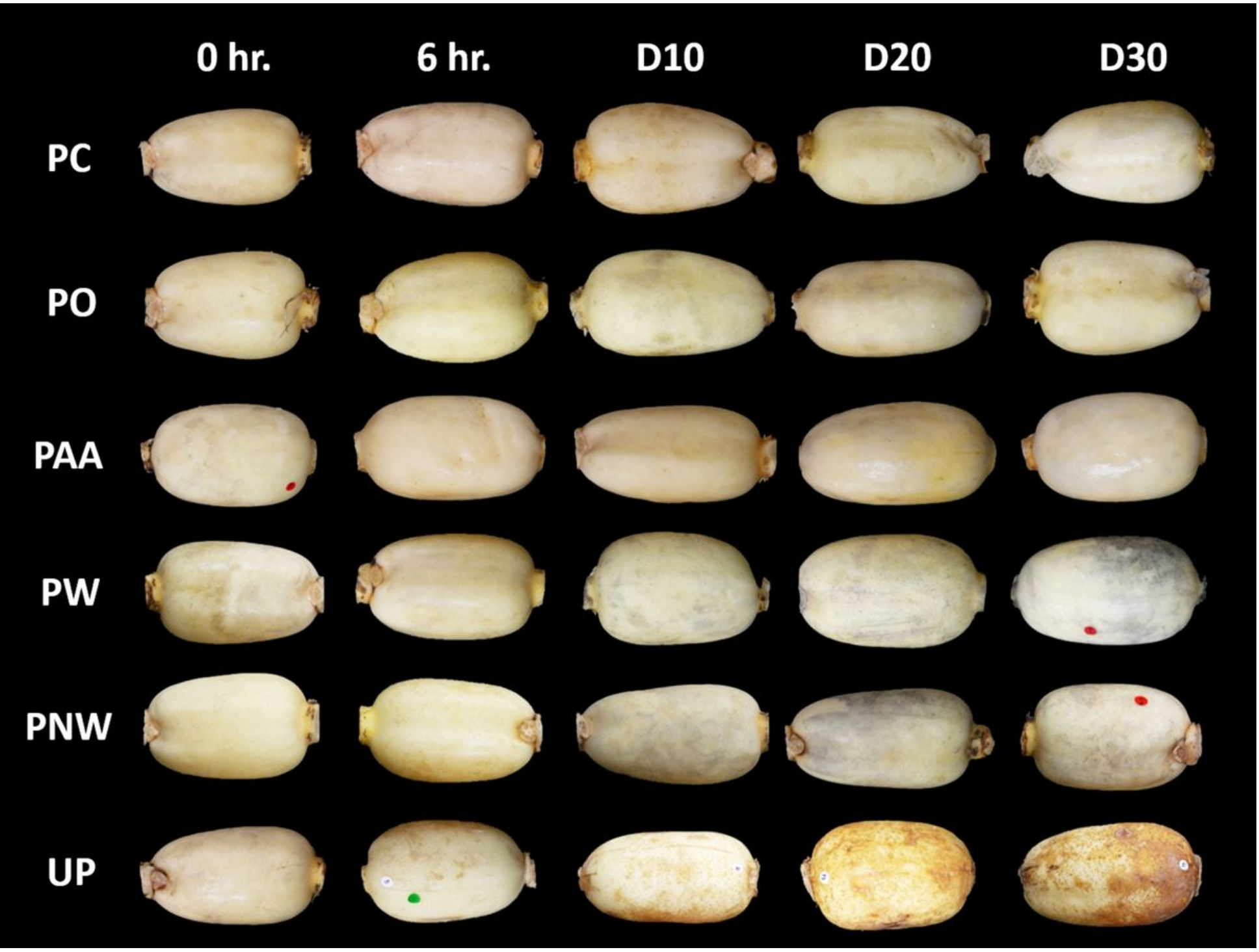

\section{Figure 3}

The appearance of lotus root after storage 0-hr., 6-hr., 10, 20, and 30 days at $5{ }^{\circ} \mathrm{C}, \mathrm{RH} 70-80 \%$ for 'Kanasumi no. 34'. (UP; unpacked, PNW; Packed no-air and no-water, PW; Packed with water, PAA; packed with $0.1 \%$ ascorbic acid solution, PO; packed with $1 \%$ onion solution, PC; packed with $0.1 \%$ citrus powder solution). 


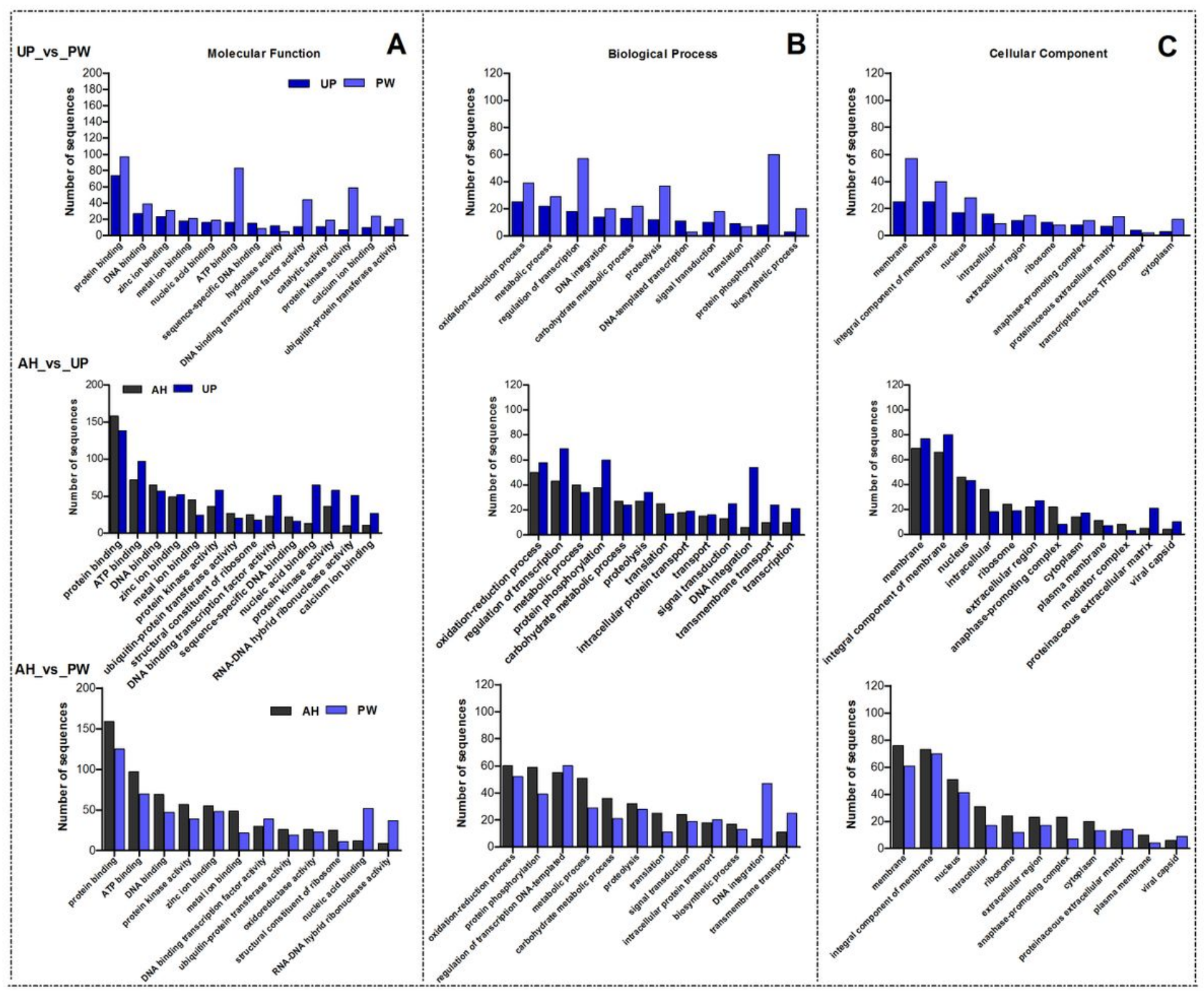

Figure 4

The histograms were showing GO functional analysis. The y-axis indicates the names of the most abundant classes in each of the three main $\mathrm{GO}$ categories. The $\mathrm{x}$-axis indicates the numbers of common DEGs. 


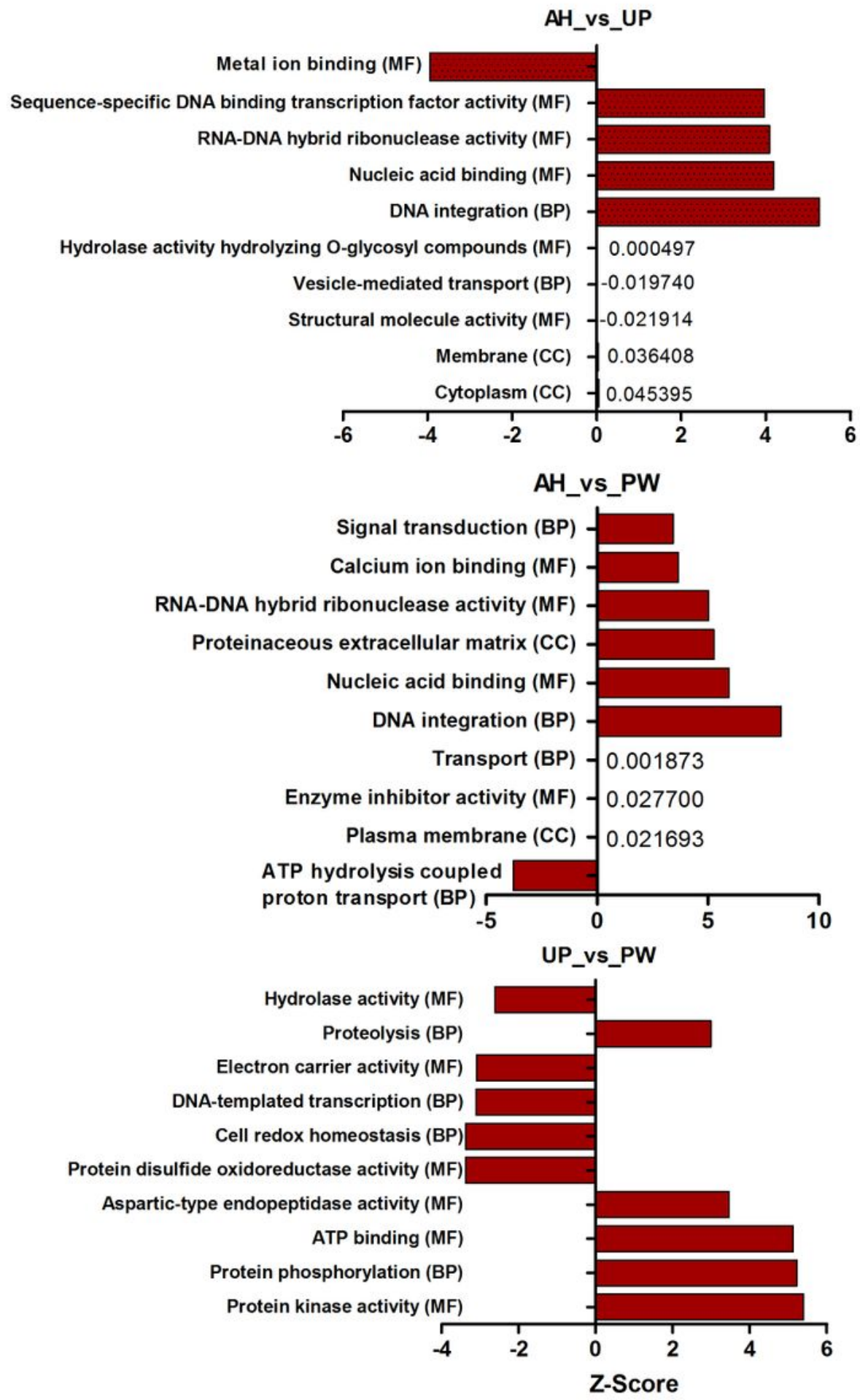

\section{Figure 5}

The histograms were showing GO functional analysis. The y-axis indicates the names of the most abundant classes in each of the three main GO categories. The x-axis indicates z-score value. 


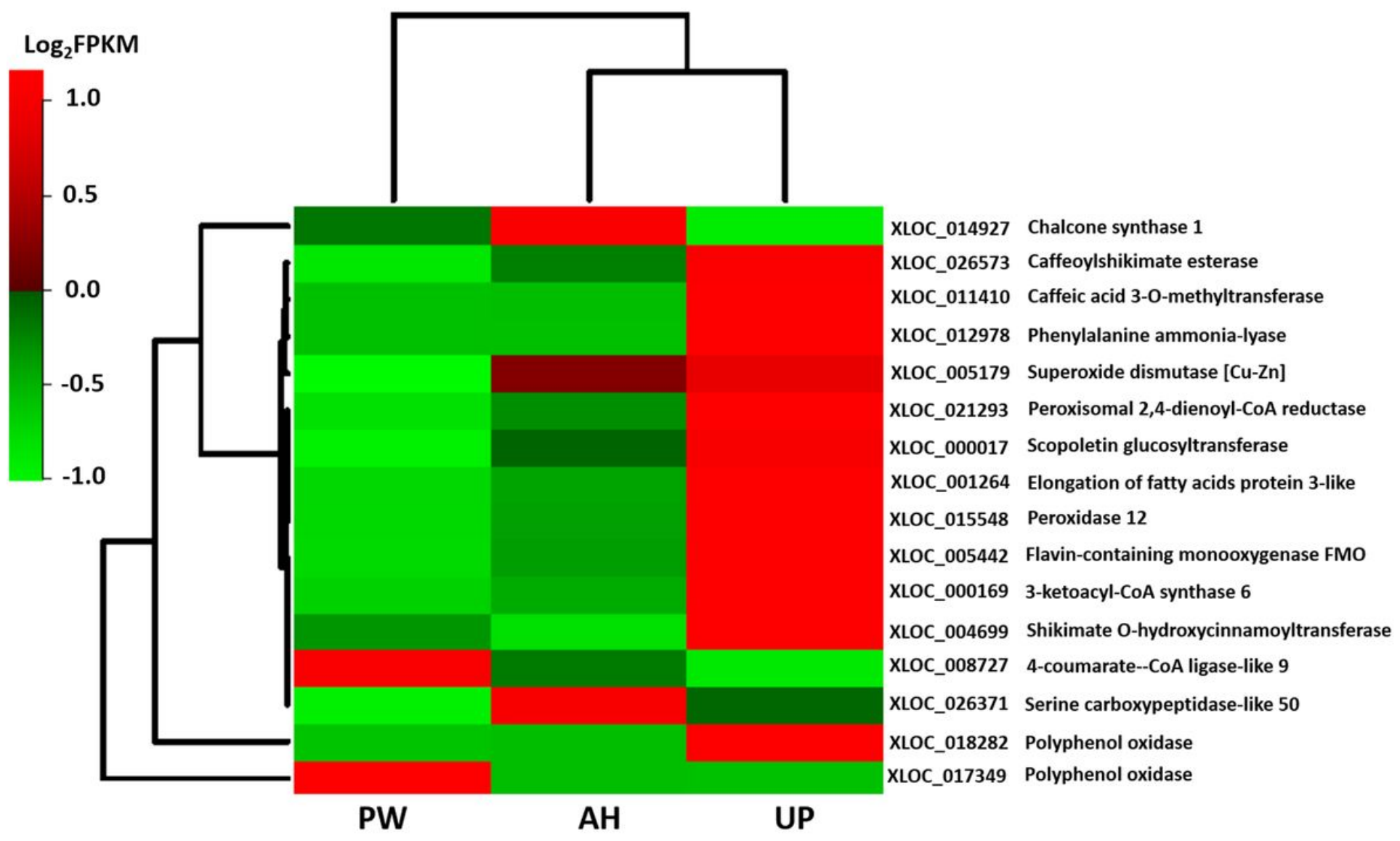

\section{Figure 6}

Heatmap visualization of sixteen key genes associated with browning. Heatmap shows the significant browning-related genes between $\mathrm{AH}, \mathrm{UP}$, and PW with q_value $\leq 0.01$ and log2-fold change $\geq 1$ (red and green colors indicate up- and downregulated transcripts, respectively). 

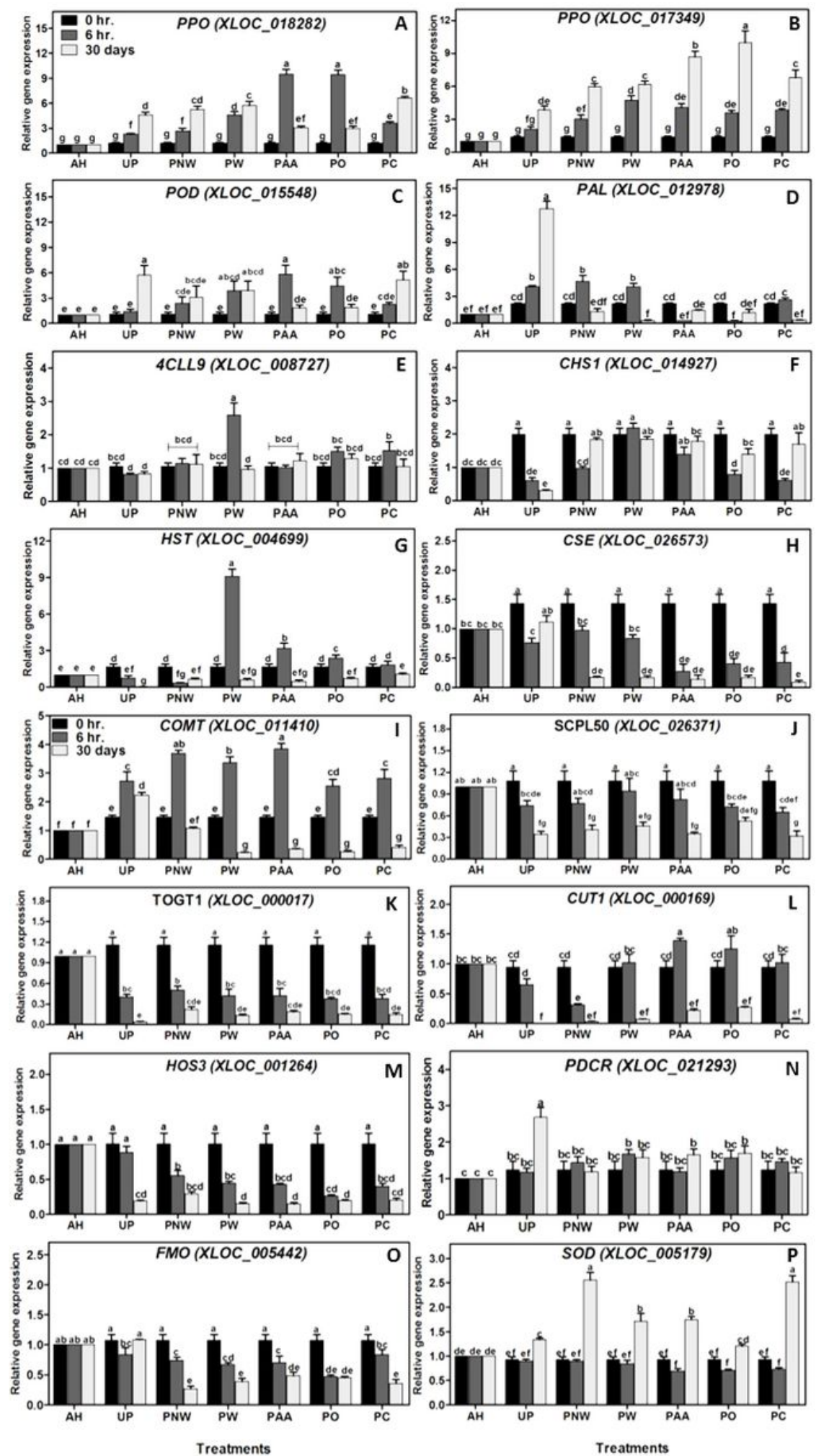

Figure 7

qRT-PCR analysis of selected sixteen genes after storage 0 -hr., 6-hr., 10,20 , and 30 days at $5{ }^{\circ} \mathrm{C}, \mathrm{RH} 70$ $80 \%$ for 'Kanasumi no. 34'. (AH; After harvest, UP; unpacked, PNW; Packed no-air and no-water, PW; Packed with water, PAA; packed with $0.1 \%$ ascorbic acid solution, PO; packed with $1 \%$ onion solution, PC; packed with $0.1 \%$ citrus powder solution). Error bars depict the standard error of the mean for three 
biological replicates. Non-overlapping letters indicate significant difference between treatments, based on ANOVA analysis and Multiple Range Tests procedure with a confidence level of $95 \%$.

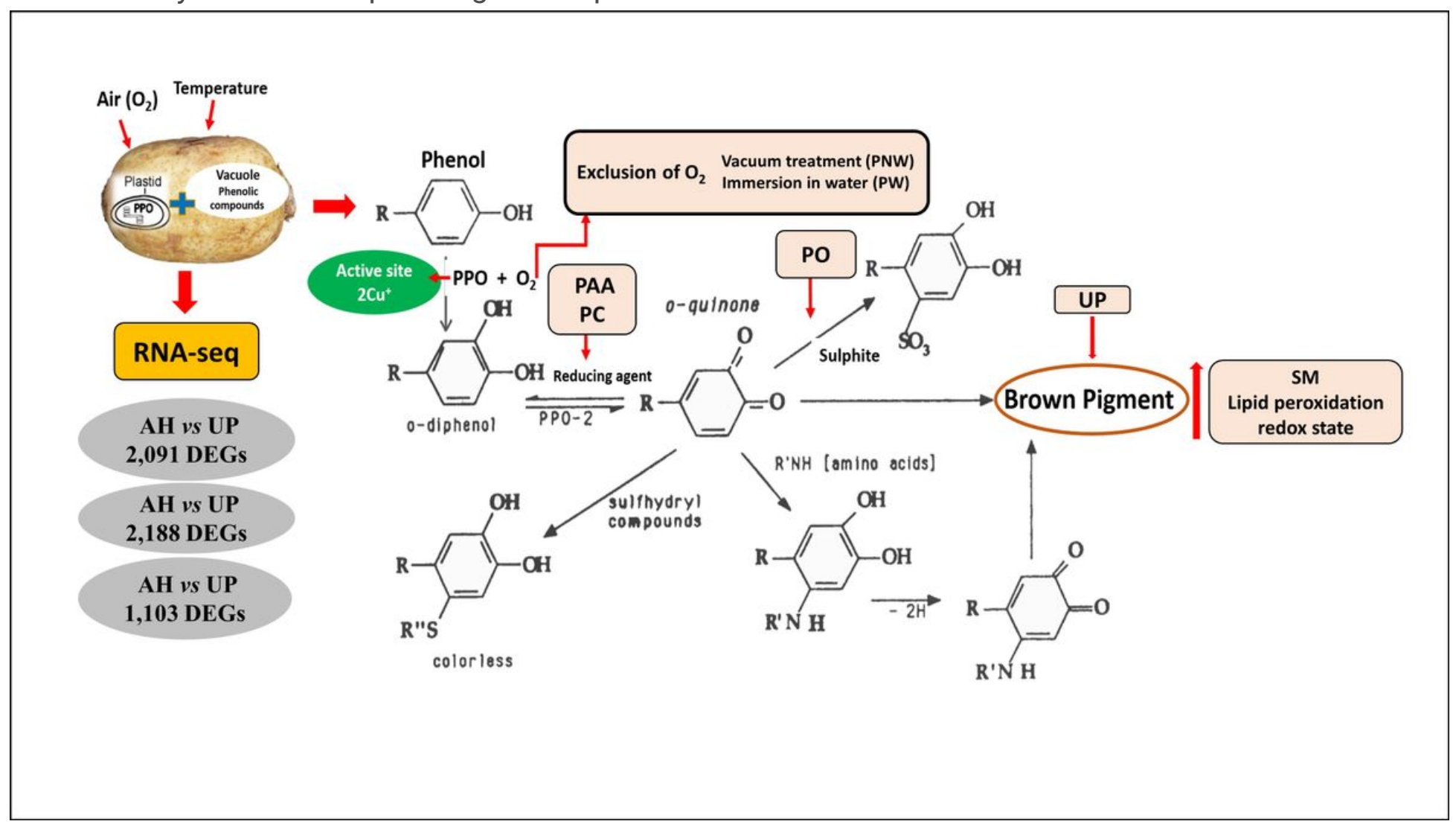

Figure 8

Simple diagram of enzymatic browning (Adapted from Grotheer et al., 2005)

\section{Supplementary Files}

This is a list of supplementary files associated with this preprint. Click to download.

- Supplementaryfiles.pdf 